\title{
The association between race/ethnicity and the prevalence of stroke among United States adults in 2015: a secondary analysis study using Behavioural Risk Factor Surveillance System (BRFSS)
}

\author{
Abdulrahman Yousef Aldayel ${ }^{1}$, Muteb Mousa Alharbi ${ }^{1}$, Asem Mustafa Shadid ${ }^{1}$, Juan Carlos Zevallos ${ }^{2}$
}

${ }^{1}$ College of Medicine, Al Imam Mohammad Ibn Saud Islamic University, Riyadh, Saudi Arabia

${ }^{2}$ Department of Medical and Population Health Sciences Research, Herbert Wertheim College of Medicine, Florida International University, Miami, FL, United States

Type of article: Original

\begin{abstract}
Background: Worldwide, stroke is considered the second leading cause of death, accounting for $11.8 \%$ of all deaths in 2013. In the Unites States (US), approximately 795,000 people have a stroke every year. Stroke has many different risk factors that vary by race/ethnicity. There is limited contemporary published literature about the prevalence of stroke among racial/ethnic groups in the US adult population.

Objective: This study aimed to determine the association between race/ethnicity and the prevalence of stroke among US adults in 2015.

Methods: This study was an observational, non-concurrent prospective of the Behavioural Risk Factor Surveillance System (BRFSS) in 2015 to assess the association between race/ethnicity and the prevalence of stroke. The final study sample was 432,814 US adults $\geq 18$ years old. Variables were excluded from the model if there were missing, refused, or did not know responses to the variables of interest. A binary logistic regression analysis was used to obtain odds ratios (OR) and 95\% confidence intervals (CI) for the association between race/ethnicity and stroke. The Chi-square test was used to study bivariate associations between categorical variables. The collinearity was assessed. A p-value of $<0.05$ was considered statistically significant. Statistical analysis was completed using STATA version 14 (Stata Corp, College Station, TX).

Results: The highest proportion of participants (43\%) were $\geq 44$ years old with a balanced distribution of males and females. The highest proportion of stroke was found among Hispanics (4.2\%) and non-Hispanic Blacks $(4.1 \%)$ as compared to $3.2 \%$ among non-Hispanic Whites $(\mathrm{p}<0.001)$. Furthermore, Hispanics and Blacks were significantly more likely to develop stroke $(\mathrm{OR}=1.57,95 \% \mathrm{CI}=1.28-1.91$; and $\mathrm{OR}=1.30,95 \% \mathrm{CI}=1.16-1.45$, respectively) after adjusting for confounding variables.

Conclusion: Hispanics and Blacks had a higher prevalence of stroke in comparison with non-Hispanic Whites. Further studies are needed to verify these findings and to determine which factors may influence the stroke differences among these racial/ethnic groups.
\end{abstract}

Keywords: Stroke; Race; Ethnicity; Hispanics; Blacks, Whites

\section{Introduction}

Stroke is a neurological deficit that leads to an acute focal injury of the central nervous system (CNS). It has a vascular cause that originates as cerebral infarction or haemorrhage (1), including intracerebral haemorrhage (ICH) and subarachnoid haemorrhage (SAH). Both worldwide and in the US, stroke is considered one of the major causes of morbidity and mortality (2). In addition, stroke is considered the second leading cause of death worldwide (ischemic heart disease is first): 6.5 million people died from a stroke in 2013, accounting for $11.8 \%$ of all deaths (3). In the US, approximately 795,000 people have a stroke every year, with 610,000 as first attacks and 185,000 as recurrent attacks (3). Stroke is often associated with poor outcomes-mortality, occurs in $15 \%$ of stroke patients and stroke is the leading cause of adult disability (4). Furthermore, in the US, an estimated $\$ 15$ to 30 billion is spent each

\section{Corresponding author:}

Abdulrahman Yousef Aldayel, College of Medicine, Al Imam Mohammad Ibn Saud Islamic University, Riyadh, Saudi Arabia. Tel.: +966549335375, Email: Ueeue2@gmail.com

Received: September 22, 2017, Accepted: November 08, 2017, Published: December 2017

iThenticate screening: November 09, 2017, English editing: November 25, 2017, Quality control: December 07, 2017 This article has been reviewed / commented by three experts

(C) 2017 The Authors. This is an open access article under the terms of the Creative Commons Attribution-NonCommercialNoDerivs License, which permits use and distribution in any medium, provided the original work is properly cited, the use is non-commercial and no modifications or adaptations are made. 
year for healthcare related to stroke (5). Prior studies in the US suggest that Blacks are more prone to strokes than are Whites, whereas there is little known about other minority groups including Hispanics $(6,7,8)$. Stroke has many different risk factors including history of high blood pressure, hyperlipidaemia, diabetes, smoking, heavy alcohol consumption, heart disease, and previous stroke or transient ischemic attacks (TIA) (9), that are distributed variably among racial/ethnic groups (10). Because of this, the incidence/prevalence of stroke is thought to vary along racial/ethnic lines (11). To our knowledge, there is limited contemporary literature about the prevalence of stroke among racial/ethnic groups in the US adult population. This study aimed to determine the association between race/ethnicity and the prevalence of stroke in the US adult population in 2015.

\section{Material and Methods}

\subsection{Study Design}

This study was an observational, non-concurrent prospective study that collected data from adult US residents ( $\geq 18$ years old) in all 50 states as well as the District of Columbia and three US territories, in 2015.

\subsection{Questionnaire}

The Behavioural Risk Factor Surveillance System (BRFSS) is a US health survey that examines many of the behavioural risk factors and conditions that place adults ( $\geq 18$ years old) at risk for chronic diseases (12). The BRFSS is a cross-sectional telephone survey that uses a multistage sampling design based on random-digit dialling methods - the world's largest such survey. From 2009, the BRFSS began conducting surveys by cellular phone in addition to traditional telephones. The questionnaire is designed by a working group of BRFSS state coordinators and the Centres for Disease Control and Prevention (CDC) staff, and is subsequently run by the CDC (12). This research addresses the core questions about the relationships between demographics (gender and age), prevalence of stroke, race/ethnicity, healthcare coverage, educational level, cigarette smoking, heavy alcohol consumption, myocardial infarction, diabetes, and hypertension (13). The BRFSS is conducted not only in the US but also by the health departments in Columbia, Guam, and Puerto Rico. All health departments are required to ask the core component questions without modifying the wording. However, the modules are optional.

\subsection{Data Collection and Processing}

Using a computer-assisted telephone interviewing (CATI) system, trained interviewers conducted BRFSS. Data collection was conducted by each state and territory every month (12). When the monthly interviewing sequence was complete, data were submitted to the CDC, which then checked the data for reliability. The dependent variable/outcome of interest was the participant's response to the question, "Has a doctor, nurse, or other health professional ever told you that you had a stroke?" The possible responses were yes, no, and don't know/not sure. The leading independent variable/exposure was determined by the response of the participant to the "five-level race/ethnicity category". The participants were asked to be categorized according to one of the following: "white only non-Hispanic, black only non-Hispanic, other race only non-Hispanic, multiracial non-Hispanic, Hispanic, and Don't know/Not sure/Refused" (14). Other relevant variables in the study of stroke were sex (male or female), age group (18 - 44, 45-54, 55-64, $\geq 65$ years old), educational level (did not graduate from high school, graduated high school, attended college or technical school, or graduated college or technical school), health care coverage (yes or no), cigarette smoking (yes or no), heavy alcohol consumption (yes or no), obesity (obese or not obese), hypertension (yes or no), diabetes (yes or no), and history of myocardial infarction (MI; yes or no).

\subsection{Data analysis}

Of the 441,456 US adults who completed the BRFSS survey (15), 432,814 were included in the study (Figure 1). Variables were excluded from the model if there were missing, refused, or did not know responses to the variables of interest. Secondary data analysis was conducted to assess the association between race/ethnicity and the prevalence of stroke, with statistical significance determined by a p-value less than 0.05 after adjusting for confounding variables using a multivariate linear regression. The Chi-square test was used to study bivariate associations between categorical variables, while the t-test was used for the continuous variables. Collinearity was assessed with the Pearson product-moment correlation. Lastly, binary logistic regression analysis was conducted to obtain odds ratios (OR) for unadjusted and adjusted models. Statistical analysis was completed using STATA version 14 (StataCorp, College Station, TX).

\subsection{Ethics}

Ethical approval was waived since the analysis involved non-human research according to the standards of the Florida International University Health Sciences Institutional Review Board (IRB). 


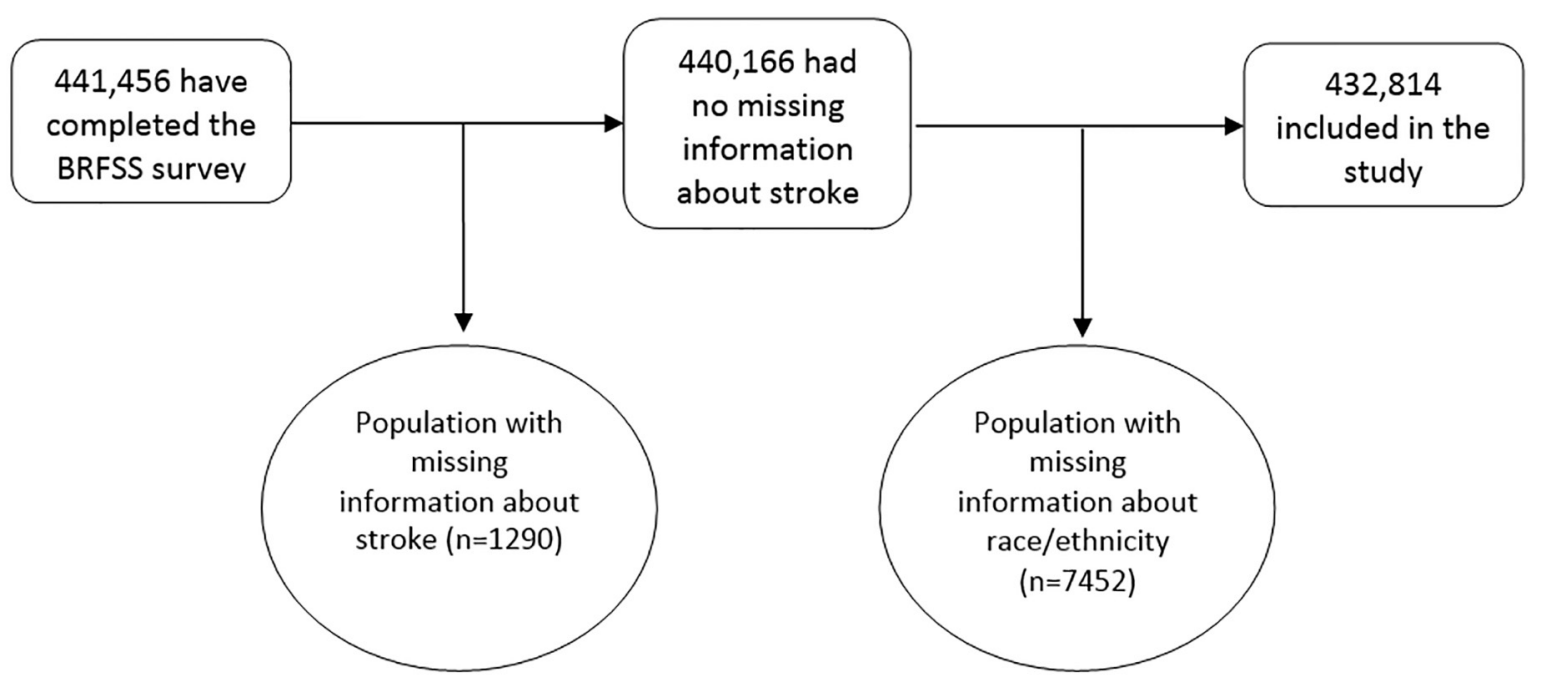

Figure 1. Inclusion criteria for study of association between race/ethnicity and the prevalence of stroke among US adult population in $2015(\mathrm{n}=432,814)$.

\section{Results}

Table 1 contains the descriptive characteristics of the study population in addition to the Chi Square analyses. The highest proportion of participants $(43 \%)$ were $\leq 44$ years old with a balanced distribution of males and females. For all racial/ethnic groups, more than $86 \%$ had at least graduated high school, with the exception of non-Hispanic other race $(37.8 \%$ did not finish high school). More than $70 \%$ of each racial/ethnic group had healthcare coverage. Hypertension and diabetes were more common among Blacks compared to other groups, with $40.5 \%$ of Blacks affected by hypertension and $14.3 \%$ by diabetes.

Table 1. Associations between race/ethnicity and some selected characteristics in the US adult population, BRFSS in 2015

\begin{tabular}{|c|c|c|c|c|c|c|c|}
\hline \multicolumn{2}{|l|}{ Characteristics } & $\begin{array}{l}\text { White, Non- } \\
\text { Hispanic; n } \\
(\%)\end{array}$ & $\begin{array}{l}\text { Black only, } \\
\text { Non-Hispanic; } \\
\text { n (\%) }\end{array}$ & $\begin{array}{l}\text { Other race only, } \\
\text { Non-Hispanic; } \\
\text { n (\%) }\end{array}$ & $\begin{array}{l}\text { Multiracial, } \\
\text { Non-Hispanic; } \\
\text { n (\%) }\end{array}$ & $\begin{array}{l}\text { Hispanic; } n \\
(\%)\end{array}$ & p-value \\
\hline \multirow[t]{4}{*}{ Age groups (year) } & $18-44$ & $75826(39.9)$ & $10571(51.3)$ & $17475(62.6)$ & $8662(59.7)$ & 3383 (61.5) & \multirow[t]{4}{*}{$<0.001$} \\
\hline & $45-54$ & $53106(17.7)$ & $6103(17.8)$ & $6535(16.2)$ & $3382(15.2)$ & $1299(14)$ & \\
\hline & $55-64$ & $77924(18.4)$ & 7944 (15.9) & 5501 (11.6) & $3558(13.7)$ & $1588(13.2)$ & \\
\hline & $\geq 65$ & $128288(24.0)$ & $9649(15.0)$ & $6177(9.63)$ & $3993(11.4)$ & $1850(11.3)$ & \\
\hline \multirow[t]{2}{*}{ Sex } & Male & $142189(48.6)$ & $12360(46.2)$ & 15098 (49.6) & $9335(49.6)$ & $3696(50.5)$ & \multirow[t]{2}{*}{$<0.001$} \\
\hline & Female & $192955(51.4)$ & $21907(53.8)$ & $20590(50.4)$ & $10260(50.4)$ & $4424(49.5)$ & \\
\hline \multirow[t]{2}{*}{ Health care coverage } & No & $17431(8)$ & $3515(14.6)$ & $7003(29.1)$ & $1777(10)$ & $708(12.0)$ & \multirow[t]{2}{*}{$<0.001$} \\
\hline & Yes & $316586(92)$ & $30602(85.4)$ & $27568(70.9)$ & $17695(90)$ & $399827(88.0)$ & \\
\hline \multirow[t]{4}{*}{ Level of education } & Under high school & $16995(8.6)$ & $4226(15.7)$ & $9907(37.8)$ & $1542(7.7)$ & $648(11)$ & \multirow[t]{4}{*}{$<0.001$} \\
\hline & High school & $922552(28.9)$ & $11255(32.6)$ & $10049(26.5)$ & $4844(19.7)$ & $2410(29)$ & \\
\hline & College candidate & $93191(32.9)$ & $9473(32.8)$ & $8131(32.6)$ & $4882(27.6)$ & $2681(37.8)$ & \\
\hline & College & $131510(29.6)$ & 9171 & 7443 & $8226(44$ & $2.2)$ & \\
\hline \multirow[t]{2}{*}{ Hypertension } & No & $198591(66.7)$ & $16000(59.5)$ & $24351(57.6)$ & $13140(76.5)$ & 5006 (70.9) & \multirow[t]{2}{*}{$<0.001$} \\
\hline & Yes & $135674(33.3)$ & $18192(40.5)$ & $11221(24.4)$ & $6387(23.5)$ & $3091(29.1)$ & \\
\hline \multirow[t]{2}{*}{ Obesity } & Not Obese & $222111(72.2)$ & $18320(62.3)$ & $21215(68)$ & $13603(84.2)$ & $5101(71.1)$ & \multirow[t]{2}{*}{$<0.001$} \\
\hline & Obese & $88345(28.8)$ & $12851(37.7)$ & $10170(32)$ & $4219(15.8)$ & $2490(28.9)$ & \\
\hline \multirow[t]{2}{*}{ Alcoholism } & No & 300161 (93.4) & $30343(95.7)$ & $31664(95.8)$ & $17239(96.4)$ & $7184(92.8)$ & $<0.001$ \\
\hline & Yes & $18279(6.6)$ & $978(4.3)$ & $1241(4.2)$ & $735(3.6)$ & $513(7.2)$ & \multirow{3}{*}{\begin{tabular}{|l|}
$<0.001$ \\
$<0.001$
\end{tabular}} \\
\hline \multirow[t]{2}{*}{ Smoking } & No & $278183(82.5)$ & $26469(80.7)$ & $29405(87.2)$ & $15173(87.5)$ & $6038(76.3)$ & \\
\hline & Yes & 45447 (17.5) & $5751(19.3)$ & $4243(12.80$ & $3207(12.5)$ & $1787(23.7)$ & \\
\hline \multirow[t]{2}{*}{ Diabetes } & No & $294524(90.2)$ & $27217(85.7)$ & $30497(89.3)$ & 16985 (89.9) & $7020(91.5)$ & \multirow[t]{2}{*}{$<0.001$} \\
\hline & Yes & $40231(9.8)$ & $6987(14.3)$ & $5096(10.7)$ & $2563(10.10$ & $1083(8.5)$ & \\
\hline \multirow{2}{*}{$\begin{array}{l}\text { Myocardial infarction } \\
\text { (MI) }\end{array}$} & Yes & $20065(4.8)$ & $1863(3.9)$ & $1356(2.8)$ & $922(2.8)$ & $536(5.1)$ & \multirow[t]{2}{*}{$<0.001$} \\
\hline & No & 313784 (95.2) & $32179(96.1)$ & $34158(97.2)$ & $18531(97.2)$ & 7540 (94.9) & \\
\hline
\end{tabular}


Table 1 also provides the Chi Square analyses of the variables of interest versus the race/ethnicity. Statistically significant differences $(p<0.001)$ in relation to race/ethnicity existed among the age groups, sex, healthcare coverage, education, smoking status, obesity, heavy alcohol consumption, hypertension, diabetes, and history of MI. The results of the logistic regression analyses are presented in Table 2. The unadjusted OR in support of an association between race/ethnicity and stroke was 1.33 for Hispanics $(95 \% \mathrm{CI}=1.10-1.61 ; \mathrm{p}<0.001)$ and 1.30 for Blacks $(95 \% \mathrm{CI}=1.17-1.41 ; \mathrm{p}<0.001)$ compared with the reference group of non-Hispanic Whites. Results of the multivariable logistic regression are also presented in Table 2. The model was controlled for sex (males or females), race/ethnicity (non-Hispanic Whites, non-Hispanic Blacks, non-Hispanic other race only, non-Hispanic multiracial, Hispanics), age group (18-44, 45-54, 55-64, $\geq 65$ years old), educational level (did not graduate from high school, graduated high school, attended college or technical school, or graduated college or technical school), health care coverage (yes or no), cigarette smoking (yes or no), heavy alcohol consumption (yes or no), obesity (obese or not obese), hypertension (yes or no), diabetes (yes or no), and history of myocardial infarction (MI; yes, no). The adjusted OR was 1.57 for Hispanics $(95 \% \mathrm{CI}=1.28-1.91 ; \mathrm{p}<0.001)$ and 1.33 for Blacks $(95 \% \mathrm{CI}=1.16$ $1.45 ; \mathrm{p}<0.001)$ compared with the reference group of non-Hispanic Whites.

Table 2. Unadjusted and adjusted association between the race/ethnicity, some selected characteristics, and prevalence of stroke in the US adult population, BRFSS in 2015

\begin{tabular}{|c|c|c|c|}
\hline \multicolumn{2}{|l|}{ Characteristics } & Unadjusted OR (95\% CI) & Adjusted OR $(95 \% \mathrm{CI})$ \\
\hline \multirow{5}{*}{ Race/Ethnicity } & White, Non-Hispanic & Ref. & Ref. \\
\hline & Black only, Non-Hispanic & $1.30(1.17-1.41)$ & $1.30(1.16-1.45)$ \\
\hline & Other race only, Non-Hispanic & $0.55(0.48-0.63)$ & $0.72(0.62-0.84)$ \\
\hline & Multiracial, Non-Hispanic & $0.63(0.53-0.76)$ & $0.97(0.78-1.2)$ \\
\hline & Hispanic & $1.33(1.1-1.61)$ & $1.57(1.28-1.91)$ \\
\hline \multirow[t]{4}{*}{ Age groups (years) } & $18-44$ & Ref. & Ref. \\
\hline & $45-54$ & $3.5(3.1-4)$ & $2.26(1.94-2.64)$ \\
\hline & $55-64$ & $6.1(5.4-6.84)$ & $3.17(2.76-3.629)$ \\
\hline & $\geq 65$ & $10.8(9.68-12.03)$ & $4.62(4.04-5.3)$ \\
\hline \multirow[t]{2}{*}{ Sex } & Male & Ref. & Ref. \\
\hline & Female & $1.05(0.99-1.12)$ & $1.17(1.09-1.25)$ \\
\hline \multirow[t]{2}{*}{ Health care coverage } & No & Ref. & Ref. \\
\hline & Yes & $1.72(1.49-1.99)$ & $1.03(0.87-1.21)$ \\
\hline \multirow[t]{4}{*}{ Level of education } & Didn't graduate from high school & $3.27(2.98-3.59)$ & $2.12(1.89-2.38)$ \\
\hline & Graduated high school & $2.08(1.93-2.25)$ & $1.51(1.39-1.65)$ \\
\hline & Attended college or technical school & $1.71(1.58-1.86)$ & $1.42(1.30-1.54)$ \\
\hline & Graduated college or technical school & Ref. & Ref. \\
\hline \multirow[t]{2}{*}{ Hypertension } & No & Ref. & Ref. \\
\hline & Yes & $5.86(5.47-6.28)$ & $2.51(2.30-2.73)$ \\
\hline \multirow[t]{2}{*}{ Obesity } & Not Obese & Ref. & Ref. \\
\hline & Obese & $1.34(1.26-1.43)$ & $0.95(0.88-1.02)$ \\
\hline \multirow[t]{2}{*}{ Heavy alcohol } & No & Ref. & Ref. \\
\hline & Yes & $0.66(0.57-0.77)$ & $0.79(0.67-0.93)$ \\
\hline \multirow[t]{2}{*}{ Cigarettes smoking } & No & Ref. & Ref. \\
\hline & Yes & $1.52(1.41-1.64)$ & $1.66(1.52-1.81)$ \\
\hline \multirow[t]{2}{*}{ Diabetes } & No & Ref. & Ref. \\
\hline & Yes & $3.93(3.68-4.21)$ & $1.44(1.33-1.56)$ \\
\hline \multirow[t]{2}{*}{ Myocardial infarction (MI) } & Yes & $10.86(10.11-11.66)$ & $4.45(4.09-4.85)$ \\
\hline & No & Ref. & Ref. \\
\hline
\end{tabular}

\section{Discussion}

This study determined that, in an adjusted logistic regression analysis, the independent relationship of race/ethnicity and stroke remains significant. Hispanics had an adjusted OR of 1.57 and Blacks had an adjusted OR of 1.33, as compared with non-Hispanic Whites. These results agree with the findings of other studies that collectively strengthen the association of stroke with the Hispanic and Black racial/ethnic groups, independent of the established risk factors of sex, age, education, cigarette smoking, and obesity $(6,8,16)$. In a study by White et al. (2005), the ischemic stroke subtype incidence was determined among Blacks, Whites, and Hispanics in northern Manhattan 
between July 1, 1993, and June 30, 1997. The study found a higher ischemic stroke incidence among Blacks and Hispanics compared with Whites in all ischemic stroke subtypes (6). Nadruz et al. (2017) published an analysis of community data collected over the past two decades. The authors indicated that the contributions of major risk factors for stroke are decreasing, probably reflecting increased awareness and treatment. Accounting for all risk factors combined, Whites experienced a greater decline in the risk of stroke between 1990 and 2010 than did Blacks. The difference was due primarily to a greater reduction in the population attributable risks (PAR) of hypertension among Whites (decrease in PAR from 66\% to 34\%; $\mathrm{P}=0.07$ ) than among Blacks (decrease in PAR from $84 \%$ to $63 \% ; \mathrm{p}=0.40$ ) (16). Sacco et al. (1995) highlighted the importance of race on intracranial atherosclerotic stroke in a community-based sample. The population sample included residents from northern Manhattan, $>39$ years old, who had been hospitalized for acute ischemic stroke ( $\mathrm{n}=438 ; 35 \%$ black, $46 \%$ Hispanic, $19 \%$ white). Atherosclerotic infarcts were subdivided into extracranial (9\%) and intracranial (8\%) atherosclerosis. The cross-sectional differences indicated that the burden of stroke risk factors increases in both Blacks and Hispanics with stroke $(p<0.05)(11)$. The limitations of this study include the self-reported nature of the data, which carries the potential of misclassification. In addition, as with all cross-sectional study designs, this study could suggest associations but could not use more powerful measurement of associations such as the risk ratio. Thus, further cohort and interventional trials studies should be conducted to verify these results. This study benefited from a large national sample size $(\mathrm{N}=432,814)$ by using the BRFSS registry from 2015 with strict inclusion criteria and validation. The sample is recent, and therefore likely reflects the current population. Finally, there is limited contemporary literature about the prevalence of stroke among racial/ethnic groups in the US adult population.

\section{Conclusions}

Hispanics and Blacks had higher odds of stroke in comparison with non-Hispanic Whites. This study bolsters literature that proposes an association between race/ethnicity and the prevalence of stroke. Stroke has many different risk factors that vary by race/ethnicity, and in certain racial/ethnic groups, we should pay more attention because their proportion of stroke incidence is higher. Further studies are needed to verify these findings and to determine which factors drive the differences in stroke incidence among these racial/ethnic groups.

\section{Acknowledgments:}

The authors would like to thank Al Imam Mohammad Bin Saud Islamic University for their support, and Florida International University for using their facilities. There was no source of fund for this study.

\section{Conflict of Interest:}

There is no conflict of interest to be declared.

\section{Authors' contributions:}

All authors contributed to this project and article equally. All authors read and approved the final manuscript.

\section{References:}

1) Sacco RL, Kasner SE, Broderick JP, Caplan LR, Connors JJ, Culebras A, et al. An updated definition of stroke for the 21st century: a statement for healthcare professionals from the American Heart Association/American Stroke Association. Stroke. 2013; 44(7): 2064-89. doi: 10.1161/STR.0b013e318296aeca. PMID: 23652265.

2) Kannel WB. Current Status of the Epidemiology of Brain Infarction Associated with Occlusive Arterial Disease. Stroke. 1971; 2(4): 295-318. doi: 10.1161/01.STR.2.4.295. PMID: 5113790.

3) Mozaffarian D, Benjamin EJ, Go AS, Arnett DK, Blaha MJ, Cushman M, et al. Heart Disease and Stroke Statistics-2016 Update: A Report From the American Heart Association. Circulation. 2016; 133(4): e38360. doi: 10.1161/CIR.0000000000000350. PMID: 26673558.

4) Williams GR. Incidence and Characteristics of Total Stroke in the United States. BMC Neurol. 2001; 1: 2. doi: 10.1186/1471-2377-1-2. PMID: 11446903, PMCID: PMC32314.

5) Dobkin B. The economic impact of stroke. Neurology, 1995; 45(2 Suppl 1): S6-9. PMID: 7885589.

6) White $\mathrm{H}$, Boden-Albala $\mathrm{B}$, Wang $\mathrm{C}$, Elkind MS, Rundek T, Wright $\mathrm{CB}$, et al. Ischemic stroke subtype incidence among whites, blacks, and Hispanics: the Northern Manhattan Study. Circulation. 2005; 111(10): 1327-31. doi: 10.1161/01.CIR.0000157736.19739. PMID: 15769776.

7) Stewart JA, Dundas R, Howard RS, Rudd AG, Wolfe CD. Ethnic differences in incidence of stroke: prospective study with stroke register. BMJ. 1999; 318(7189): 967-71. doi: 10.1136/bmj.318.7189.967. PMID: 10195965, PMCID: PMC27822. 
8) Kittner SJ, White LR, Losonczy KG, Wolf PA, Hebel JR. Black-white differences in stroke incidence in a national sample. The contribution of hypertension and diabetes mellitus. JAMA. 1990; 264(10): 1267-70. doi: 10.1001/jama.1990.03450100057025. PMID: 2388378.

9) Fogle CC, Oser CS, Troutman TP, McNamara M, Williamson AP, Keller M, et al. Public Education Strategies to Increase Awareness of Stroke Warning Signs and the Need to Call 911. J Public Health Manag Pract. 2008; 14(3): e17-22. doi: 10.1097/01.PHH.0000316496.78282.47. PMID: 18408540.

10) Bravata DM, Wells CK, Gulanski B, Kernan WN, Brass LM, Long J, et al. Racial disparities in stroke risk factors: the impact of socioeconomic status. Stroke. 2005; 36(7): 1507-11. doi: 10.1161/01.STR.0000170991.63594.b6. PMID: 15961710.

11) Sacco RL, Kargman DE, Zamanillo MC. Race-ethnic differences in stroke risk factors among hospitalized patients with cerebral infarction: The Northern Manhattan Stroke Study. Neurology. 1995; 45(4): 659-63. doi: 10.1212/WNL.45.4.659. PMID: 7723951.

12) About the Behavioral Risk Factor Surveillance System (BRFSS). U.S. Department of Health and Human Services, Centers for Disease Control and Prevention; 2013.

13) Behavioral Risk Factor Surveillance System operational and user's guide. U.S. Department of Health and Human Services, Centers for Disease Control and Prevention; 2006.

14) Behavioral Risk Factor Surveillance System questionnaire. U.S. Department of Health and Human Services, Centers for Disease Control and Prevention; 2015.

15) Behavioral Risk Factor Surveillance System Survey Data. U.S. Department of Health and Human Services, Centers for Disease Control and Prevention; 2015.

16) Nadruz W Jr, Claggett B, Henglin M, Shah AM, Skali H, Rosamond WD, et al. Racial Disparities in Risks of Stroke. N Engl J Med. 2017; 376(21): 2089-90. doi: 10.1056/NEJMc1616085. PMID: 28538119, PMCID: PMC5613984. 